\title{
Prochlorococcus extracellular vesicles: molecular composition and adsorption to diverse microbes
}

\author{
Steven J. Biller ${ }^{1 D},{ }^{1,2 *}$ Rachel A. Lundeen ${ }^{(D,}{ }^{3}$ \\ Laura R. Hmelo, ${ }^{3}$ Kevin W. Becker $\mathbb{D}^{4},{ }^{4} \dagger$ \\ Aldo A. Arellano, ${ }^{1}$ Keven Dooley, ${ }^{1}$ Katherine R. Heal (D), ${ }^{3 *}$ \\ Laura T. Carlson, ${ }^{3}$ Benjamin A. S. Van Mooy, ${ }^{4}$ \\ Anitra E. Ingalls ${ }^{3}$ and Sallie W. Chisholm ${ }^{1 \S}$ \\ ${ }^{1}$ Department of Civil and Environmental Engineering, \\ Massachusetts Institute of Technology, Cambridge, MA. \\ ${ }^{2}$ Department of Biological Sciences, Wellesley College, \\ Wellesley, MA. \\ ${ }^{3}$ School of Oceanography, University of Washington, \\ Seattle, WA. \\ ${ }^{4}$ Department of Marine Chemistry and Geochemistry, \\ Woods Hole Oceanographic Institution, Woods \\ Hole, MA.
}

\section{Summary}

Extracellular vesicles are small ( $\sim 50-200 \mathrm{~nm}$ diameter) membrane-bound structures released by cells from all domains of life. While vesicles are abundant in the oceans, their functions, both for cells themselves and the emergent ecosystem, remain a mystery. To better characterize these particles - a prerequisite for determining function - we analysed the lipid, protein, and metabolite content of vesicles produced by the marine cyanobacterium Prochlorococcus. We show that Prochlorococcus exports a diverse array of cellular compounds into the surrounding seawater enclosed within discrete vesicles. Vesicles produced by two different strains contain some materials in common, but also display numerous strain-specific differences, reflecting functional complexity within vesicle populations. The vesicles contain active enzymes, indicating that they can mediate extracellular biogeochemical reactions in the ocean. We further demonstrate that vesicles from Prochlorococcus and other bacteria associate with diverse microbes including the most abundant marine bacterium, Pelagibacter. Together, our data

Received 18 December, 2020; accepted 29 October, 2021. *For correspondence. E-mail sbiller@wellesley.edu. Present addresses: ${ }^{\dagger}$ GEOMAR Helmholtz Centre for Ocean Research Kiel, Kiel; "Integral Consulting Inc, Seattle, WA; ${ }^{\circledR}$ Department of Biology, Massachusetts Institute of Technology, Cambridge, MA. point toward hypotheses concerning the functional roles of vesicles in marine ecosystems including, but not limited to, possibly mediating energy and nutrient transfers, catalysing extracellular biochemical reactions, and mitigating toxicity of reactive oxygen species.

\section{Introduction}

Many, if not all, bacteria release extracellular vesicles from their surface into the local environment (Deatherage and Cookson, 2012). In exponentially growing Gramnegative bacteria, these structures are thought to derive primarily from the outer membrane, wherein a local region of membrane separates from the cell, carrying with it periplasmic material and other cellular components (Schwechheimer and Kuehn, 2015). A small subset of vesicles from Gram-negative cells may include both outer and inner membrane material as well, further expanding the range of potential vesicle contents (Pérez-Cruz et al., 2015). Vesicles are released constitutively during growth, but release rates can also vary in response to environmental perturbations (MacDonald and Kuehn, 2013; Biller et al., 2014). Extracellular vesicles represent a versatile secretion mechanism for cells (Schwechheimer and Kuehn, 2015; Guerrero-Mandujano et al., 2017), and many classes of cellular compounds, including proteins, nucleic acids, and small molecules, have been identified within bacterial vesicles (Schwechheimer and Kuehn, 2015; Brown et al., 2015). Since they are bounded by a lipid bilayer membrane, vesicles also provide a mechanism for secreting and transporting hydrophobic compounds through aqueous extracellular environments (Mashburn-Warren and Whiteley, 2006).

Extracellular vesicles can shuttle their contents between cells (Kadurugamuwa and Beveridge, 1996; Yaron et al., 2000). This ability enables vesicles to mediate a wide variety of biological functions such as horizontal gene transfer, signalling, pathogenesis, quorum signalling, biofilm development, nutrient exchange, viral interactions, and cellular defence (Kadurugamuwa and Beveridge, 1996; Yaron et al., 2000; MacDonald and Kuehn, 2012; Schwechheimer and Kuehn, 2015; Lynch and Alegado, 2017; Schatz et al., 2017). Although such 


\section{S. J. Biller et al.}

exchanges have been shown to occur both among bacteria and across domains in a few laboratory models, the 'rules' dictating these exchanges are not at all clear, and essentially nothing is known about what occurs between cells and vesicles in complex microbial systems such as those found in the oceans, soils, or within the human microbiome.

Extracellular vesicles can reach concentrations of $>10^{5}$ and $>10^{6} \mathrm{ml}^{-1}$ in open ocean and coastal waters, respectively (Biller et al., 2014) and represent an entirely new dimension of dissolved organic carbon pools. Their biological and ecological roles are unknown, but we do know that they are released by diverse taxa of both autotrophic and heterotrophic marine microbes, including the abundant cyanobacterium Prochlorococcus (Biller et al., 2014). With a global population of $\sim 3 \times 10^{27}$ cells, Prochlorococcus is an important primary producer, responsible for nearly $10 \%$ of marine net primary production (Flombaum et al., 2013). This group is known to secrete a number of organic compounds (Bertilsson et al., 2005) that provide marine heterotrophs with a source of carbon and energy (Ottesen et al., 2014; Becker et al., 2019) and contribute to marine dissolved organic carbon pools. Prochlorococcus extracellular vesicles represent at least one component of this labile organic photosynthate, as purified vesicles have been shown to support the growth of a marine heterotroph (Biller et al., 2014).

Here, we explore the contents and function of extracellular vesicles produced by Prochlorococcus, focusing on their potential contribution to ocean dissolved organic matter and their ability to interact with other marine microbes. We characterized the lipidome, proteome, and metabolome of vesicles released by two ecologically distinct strains and use these inventories to develop hypotheses of vesicle functions. To establish whether Prochlorococcus vesicles can chemically interact with surrounding seawater, we determined whether they contain active enzymes. Finally, we investigated the potential for Prochlorococcus vesicles to mediate biotic interactions by studying whether they can form specific associations with other strains representative of abundant marine microbes.

\section{Results and discussion}

Diverse biomolecules are associated with

Prochlorococcus extracellular vesicles

We used a combination of targeted and untargeted 'omics' approaches to examine the contents of vesicles and the cells that released them. Our study focused on vesicles isolated from exponentially growing, asynchronous cultures of two ecologically distinct Prochlorococcus - MIT9312, a high-light adapted strain, and MIT9313, a low-light adapted strain (Biller et al., 2015a,b). We uncovered a vast diversity of biomolecules in these discrete, lipid-bound, colloidal packets, as detailed below.

Lipids and pigments. Lipids from vesicles and cells of both Prochlorococcus strains were analysed using an untargeted, high-resolution mass spectrometry-based approach. Vesicles contained a suite of different intact polar lipids (IPLs), various pigments, and plastoquinone. Overall, vesicles were relatively enriched for IPLs verus pigments, as compared with the parent cells (Fig. 1A; Supporting Information Table S1). The carotenoids zeaxanthin and carotene were the most abundant pigments in vesicles from both strains, which contained relatively few chloropigments such as divinyl chlorophylls $a$ and $b$ (Fig. 1B; Supporting Information Table S1). While plastoquinone was identified in the vesicles (Fig. 1B; Supporting Information Table S1), they contained little thylakoid material overall, suggesting that vesicle carotenoids could come from other cellular locations such as the outer membrane, as has been shown for Synechocystis PCC6714 (Jürgens and Weckesser, 1985).

Prochlorococcus cellular membranes are primarily composed of sulfolipids, reflecting an adaptation to the low phosphorous oligotrophic environment in which they live (Van Mooy et al., 2006). This was evident in the lipid composition of its extracellular vesicles as well. The IPL composition of Prochlorococcus extracellular vesicles was dominated by sulfoquinovosyl diacylglycerol (SQDG), diglycosyl diacylglycerol (DGDG) and monoglycosyl diacylglycerol (MGDG) - each found in similar relative abundances (as a proportion of all IPLs) in cells and vesicles (Fig. 1C; Supporting Information Table S1). The overall vesicle lipid composition of each strain more closely resembled the composition of the parent cells than the vesicles from the other strain (Figs. 1C and S1), consistent with our previous observations from Prochlorococcus strains MIT9313 and MED4 (Biller et al., 2014) suggesting that there is not a universal Prochlorococcus vesicle lipidome. Vesicles from the two strains did, however, share some common lipid features that distinguished them from the parental cells. Of note, hydroxylated forms of all major IPLs identified (polar lipids modified by oxidation reactions) were relatively more abundant in vesicle samples as compared with cells (Fig. 1D; Supporting Information Table S1). In addition, the fraction of some hydroxylated IPLs (DGDG in MIT9312; SQDG and MGDG in MIT9313) among biological replicate vesicle samples was significantly more variable than in the corresponding cellular samples ( $F$-test, $P<0.05$; Figs. 1D and S1B-D). Annotation of these hydroxylated lipids revealed that the hydroxylation is site specific, for example, at the $\Delta 9$-position of a $\mathrm{C}_{18: 2}$ fatty acid (Supporting Information Fig. S2) regardless of head 
A

pigments vs. intact polar lipids
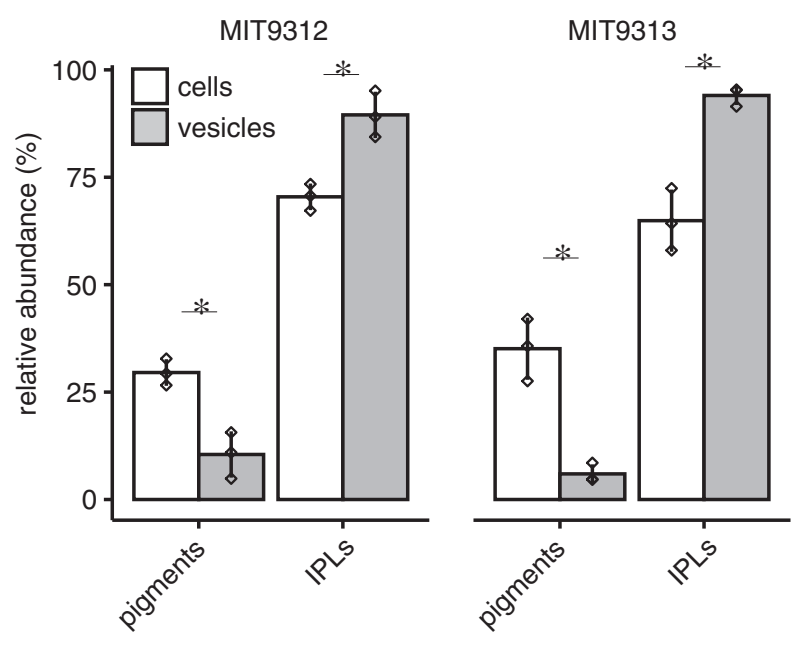

C intact polar lipids

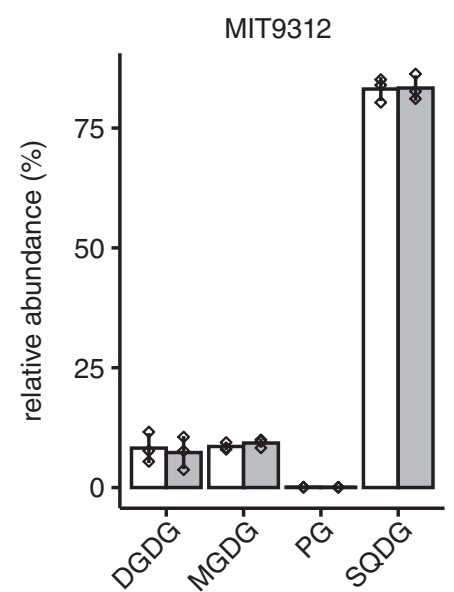

B

pigments and plastoquinone

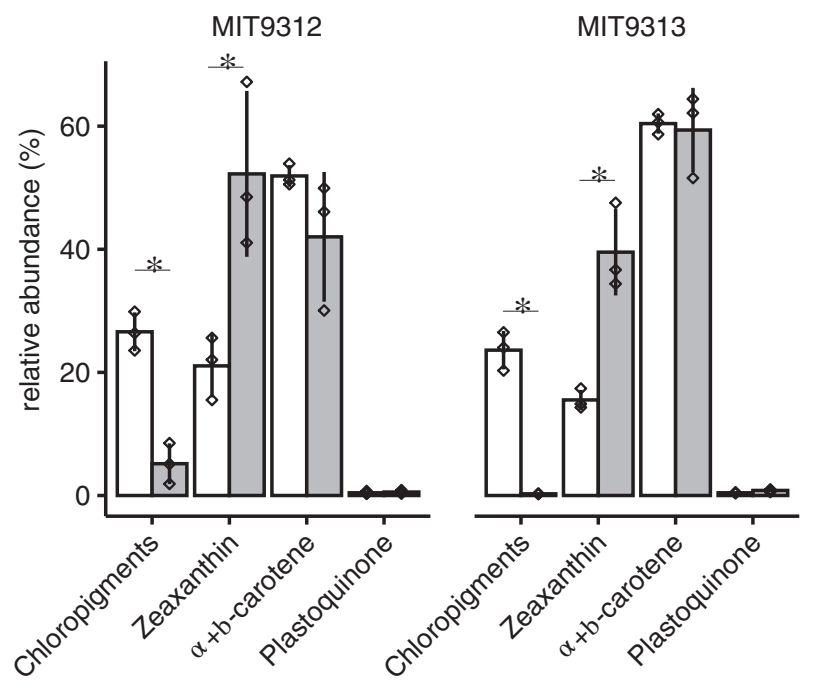

hydroxylated polar lipids

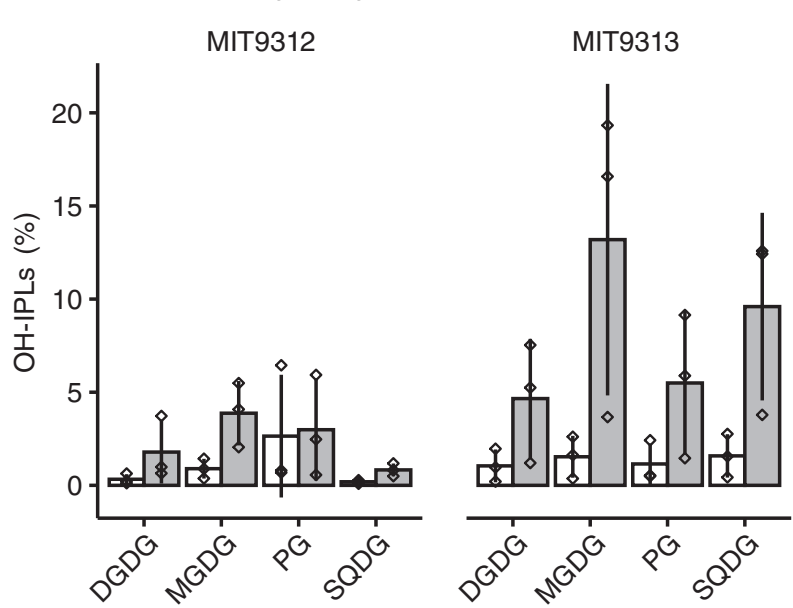

Fig. 1. Lipid and pigment content of Prochlorococcus cells and vesicles from two strains, MIT9312 and MIT9313.

A. Relative abundance of pigments vs intact polar lipids (IPLs) in vesicles and cells.

B. Relative abundance of specific pigments and plastoquinone.

C. Relative abundance of different IPL groups.

D. Fraction of hydroxylated polar lipids (OH-IPLs) within each IPL class. Values indicate the mean ( \pm SD) of three biological replicates of strains MIT9312 (white) and MIT9313 (black). MGDG: monoglycosyl diacylglycerol; DGDG: diglycosyl diacylglycerol; PG: phosphatidylglycerol; SQDG: sulfoquinovosyl diacylglycerol. * indicates significant differences between cells and vesicles (two-tailed $t$ test, $P<0.05$ ).

group. The exact oxidative mechanism (enzymatic, radical mediated, or non-radical mediated) responsible for generating the hydroxylation is not known, but freeradical (auto) oxidation at a specific double bond would be expected to result in at least four isomers of similar abundance (Rontani and Belt, 2020). While lipid hydroxylation could have occurred either before or after vesicle release, the site-specificity raises the possibility that they could be of biological origin. One potential explanation is that Prochlorococcus outer membranes are generally enriched in hydroxylated lipids relative to other membranes, as has been shown for other Gram-negative bacteria (Schmidt et al., 1980; Volkman et al., 1998). This would be consistent with their enrichment in outer membrane-derived vesicles and perhaps reflect a role for vesicle secretion as a mechanism for removing damaged lipids from the cell. Hydroxylipids may also be involved in the membrane curvature and bending processes required for vesicle formation, leading to their preferential incorporation and export. 


\section{S. J. Biller et al.}

Proteins. Since many of the functional roles attributed to vesicles in other microbial systems are due to the activity of proteins (Schwechheimer and Kuehn, 2015), we explored the global proteomes of the vesicle and cellular fractions of two Prochlorococcus strains using a labelfree, quantitative shotgun proteomics approach. During extraction and sample preparation, we utilized surfactants compatible with mass spectrometry to improve the recovery of more membrane-bound proteins and better facilitate in-solution protease digestion, which further helped generate more comprehensive vesicle and cellular proteomes. MIT9312 and MIT9313 vesicles contained, respectively, at least $11 \%$ and $12.5 \%$ of all predicted proteins encoded by the cell's genome (Table 1). This most likely does not represent every protein found in vesicles, but rather what could be detected within the relatively small amount of vesicle biomass we could obtain from 20 I cultures as compared with cellular material (c.f., cellular proteomes for MIT9312 and MIT9313 recovered nearly $52 \%$ and $37 \%$ of all predicted proteins, respectively; Table 1). That said, these vesicle proteomes yielded notably more protein identifications than our previous study of MIT9313 and MED4 vesicles (in which gelextracted protein bands were analysed; Biller et al., 2014), and it is noteworthy that 25 of the 27 proteins we previously identified in MIT9313 were also present in this data set. Further, those 25 were among the top 50 most highly abundant proteins in the MIT9313 vesicle proteome (Supporting Information Tables S2 and S3). The concordance of these results shows that Prochlorococcus cells grown under similar conditions will reproducibly package and export intact proteins within vesicles.

Vesicles produced by the two Prochlorococcus strains contained some proteins in common (Tables 1 and S2), but we also noted strain-specific differences, as has been found in comparisons of vesicles from other closely related microbes (Tandberg et al., 2016; Bitto et al., 2021). The overall Prochlorococcus vesicle proteome included proteins associated with many functional categories (Figs. 2A, S3). For instance, both MIT9312 and MIT9313 vesicles contained putative porins and transporters (e.g. PMT9312_1131, Som), peptidases/ hydrolases (e.g. PMT9312_0677, PMT_1636), chaperones (e.g. DnaK and DnaJ), and uncharacterized proteins (Fig. S3; Table S4). The relative abundance of these shared proteins did, however, vary between strains (Fig. 2A; Tables S2-S4). Proteins uniquely found in MIT9312 vesicles included a cAMP phosphodiesterase (PMT9312_0858), an adhesin-like protein (PMT9312_1179), a phosphate ABC transporter substrate-binding protein (PstB), and some ribosomal proteins. Among those found uniquely in MIT9313 were multiple $A B C$ transporter binding proteins (e.g. UrtA, FutA1, PMT_2203), a sulfatase (PMT_1515), and a putative phosphatase (PMT_1619) (Fig. 2A; Tables S2 and S3). Thus, the vesicles released by two relatively similar organisms have distinct functional potentials.

The functional potential of vesicles will also be influenced by the relative abundance of any individual protein within the vesicle population. Indeed, different proteins were packaged at different levels within the vesicles in our samples, with a subset enriched (on a biovolume-normalized basis) in vesicles relative to cells (Figs. 2A, S4; Table S4). To explore what factors might influence the packaging, we examined whether subcellular localization correlated with vesicle export. Consistent with a primarily outer membrane origin for extracellular vesicles, most outer membrane and periplasmic proteins detected in the cellular proteome were identified at some level within vesicles (Fig. S5). As seen in other Gramnegative bacteria (Pérez-Cruz et al., 2015; Zakharzhevskaya et al., 2017; Yun et al., 2017), we found proteins from all major cellular regions to be exported within Prochlorococcus vesicles (Fig. 2B). We were, however, surprised to find that cytoplasmic proteins made up the largest fraction in strain MIT9312, whereas most proteins in MIT9313 vesicles were predicted to originate from various locations outside the cytoplasm (Fig. 2B). Although a number of abundant cytoplasmic proteins, such as ribosomal proteins, were found in MIT9312 vesicles (Fig. 2A; Tables S2 and S3), there was no general relationship between their abundance in the cells and vesicles (Supporting Information Fig. S6A). Together with the relative lack of thylakoid proteins and chlorophyll in the vesicles, this argues that the presence

Table 1. Number of proteins identified in Prochlorococcus cells and vesicles.

\begin{tabular}{|c|c|c|c|c|c|c|c|}
\hline Strain & $\begin{array}{l}\text { Annotated proteins } \\
\text { encoded in } \\
\text { genomes (Uniprot) }\end{array}$ & $\begin{array}{c}\text { Annotated } \\
\text { proteins shared } \\
\text { by both } \\
\text { genomes }\end{array}$ & $\begin{array}{l}\text { Proteins } \\
\text { detected } \\
\text { in cells }{ }^{a}\end{array}$ & $\begin{array}{l}\text { Proteins } \\
\text { detected in } \\
\text { cells of both } \\
\text { strains }\end{array}$ & $\begin{array}{l}\text { Proteins } \\
\text { detected in } \\
\text { vesicles }\end{array}$ & $\begin{array}{l}\text { Proteins detected } \\
\text { only in vesicles } \\
\text { and not in cells }\end{array}$ & $\begin{array}{l}\text { Proteins detected } \\
\text { in vesicles from } \\
\text { both strains }\end{array}$ \\
\hline MIT9312 & 1964 & 1532 & 1030 & 714 & 224 & 17 & 111 \\
\hline MIT9313 & 2830 & & 1055 & & 355 & 41 & \\
\hline
\end{tabular}

${ }^{a}$ These values reflect the data gathered for the trypsin/Lys-C digestion of Prochlorococcus cells and vesicles (Supporting Information Tables S2 and S3); not included here, additional cellular proteins were identified using Glu-C digestion. 
A

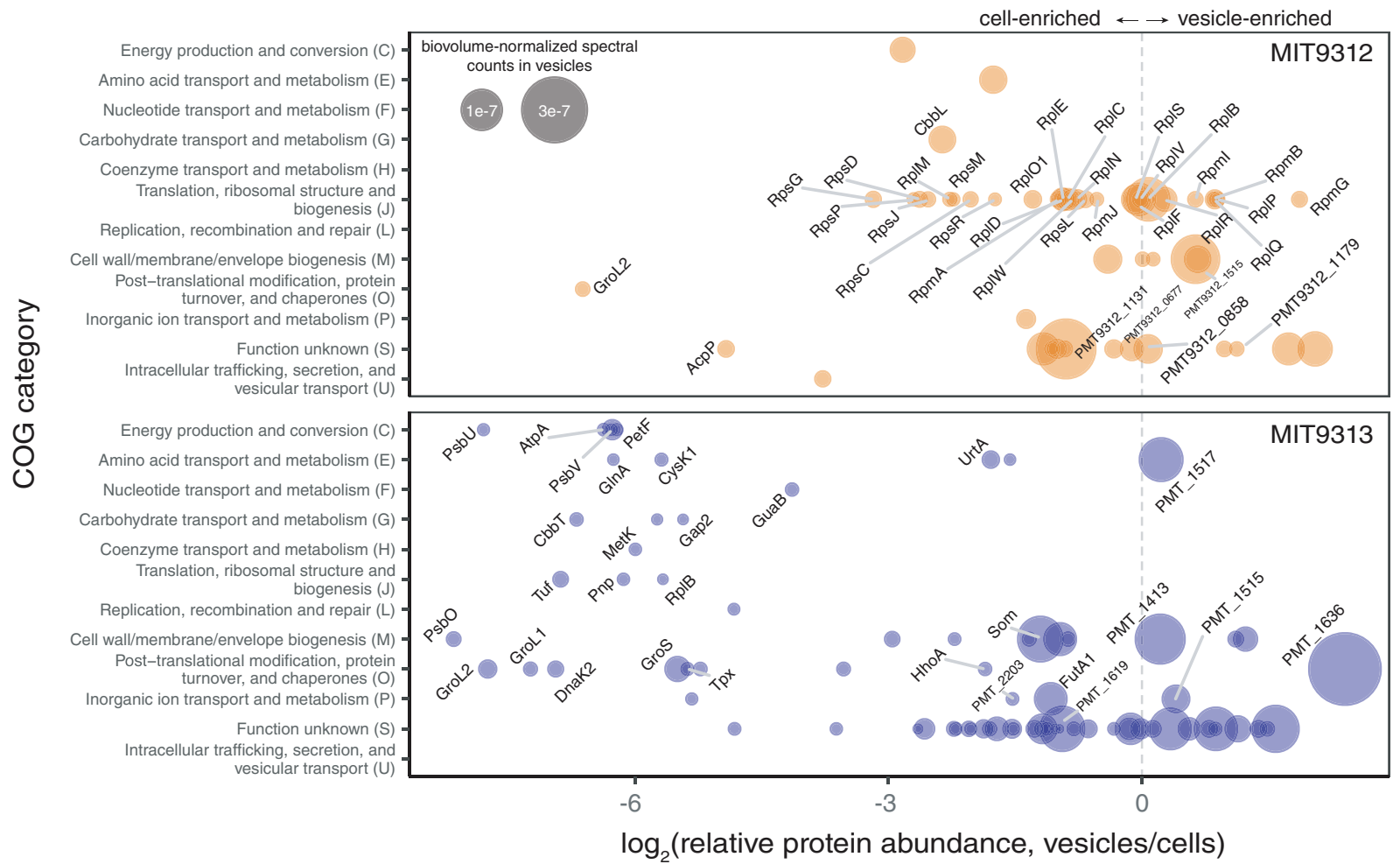

B

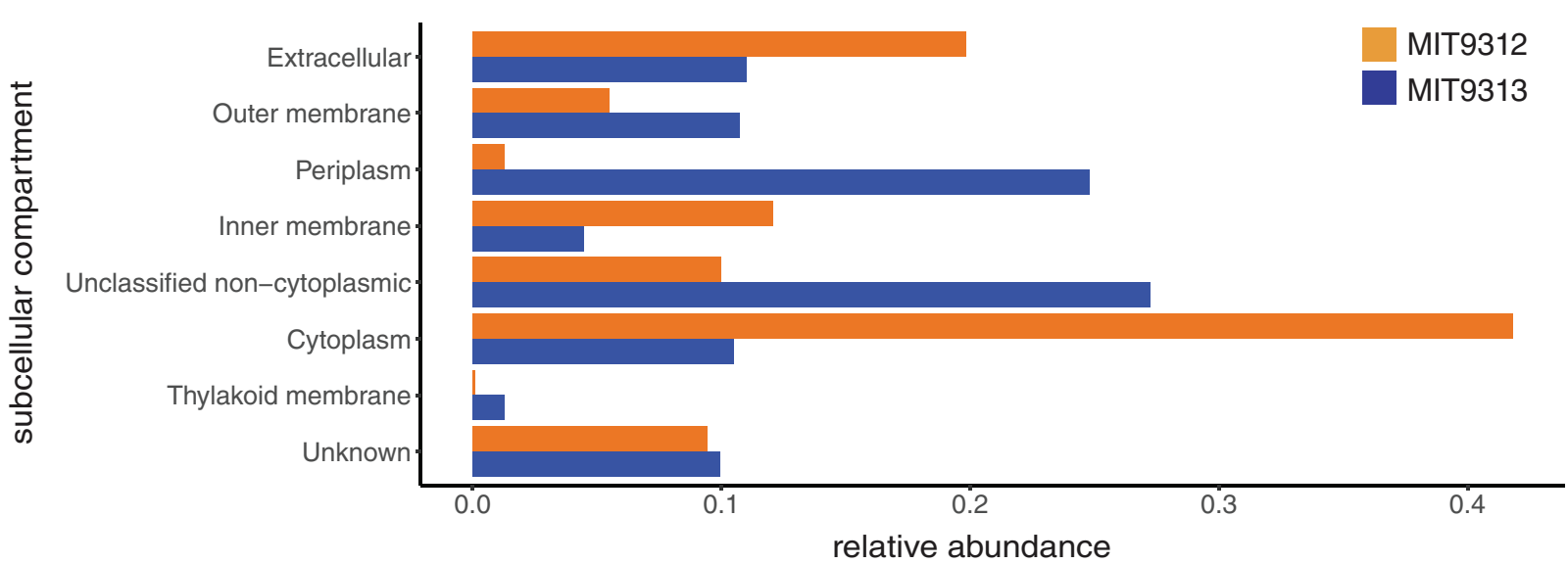

Fig. 2. Prochlorococcus vesicle proteomes.

A. Relative protein enrichment in Prochlorococcus vesicles compared with cells. Points represent the $\log _{2}$ ratio of relative protein abundance for the top 25\% most abundant proteins identified in vesicles of strain MIT9312 (above; orange) or MIT9313 (below; blue), as grouped by NCBI clusters of orthologous groups of proteins (COG) functional categories. The area of each point indicates biovolume-normalized spectral counts (abundance) of that protein within the vesicle proteome. Names or locus tags are indicated for selected proteins; data for all vesicle proteins are found in the Supporting Information Table S4.

B. Relative abundance of proteins found in MIT9312 (orange) and MIT9313 (blue) vesicles, as grouped by predicted subcellular localization (see Methods).

of cytosolic proteins is likely not due to artefacts such as cell lysis. We also saw no clear relationship between a protein's presence in the vesicles and properties such as isoelectric point or molecular weight (Supporting Information Fig. S6B-E).

A number of factors likely contribute to the differences observed between the vesicle proteomes of the two strains. Some differences are simply attributable to strain-specific genomic differences (Table 1). While the two genomes share over 1500 genes, MIT9313 encodes $\sim 870$ more genes than does MIT9312, and its vesicles contained a proportionally more diverse set of proteins. One notable example was the identification of several prochlorosins, or ProcA peptides, within the vesicle 
proteome of MIT9313 (Supporting Information Table S2). Prochlorosins are cyclic peptide secondary metabolites encoded by some low-light adapted, but not high-light adapted, Prochlorococcus - including 29 diverse procA genes in MIT9313 (Li et al., 2010; Cubillos-Ruiz et al., 2017). Strain-specific genome differences do not, however, explain all of the vesicle proteome variation. Even when considering only the proteins shared by both strains, we found that the relative abundance of orthologous proteins was linearly correlated in the whole cell fraction, but that there was no clear relationship in the relative amounts of these proteins within extracellular vesicles (Supporting Information Fig. S4B). We speculate that differences in cellular structure between the strains (Ting et al., 2007) may have influenced the differential incorporation of proteins from the cytosol and other subcellular compartments into vesicles.

While we cannot rule out the possibility that some individual proteins were specifically packaged via unknown mechanisms, our data suggest that most proteins are packaged stochastically, with the probability of export influenced by a number of factors including initial cellular protein abundance, subcellular localization, and perhaps strain-specific differences in cellular architecture. Physical constraints, such as the amount of membrane relative to the aqueous lumen of the vesicle, may also influence protein composition and limit the enrichment of some compounds in vesicles relative to cells (Turner et al., 2018). Finally, it is likely that additional sampling would reveal an even longer 'tail' of other proteins that are either exported at relatively lower abundances or were perhaps lost through the purification protocols used here. Thus, we suspect that most (or perhaps all) proteins expressed within cells will eventually be found within vesicle populations. Future work examining vesicles across strains (Tartaglia et al., 2020; Zwarycz et al., 2020) and under different growth conditions (Orench-Rivera and Kuehn, 2016; Zavan et al., 2019) will be needed to advance our understanding of the mechanisms influencing vesicle proteome composition, and how such differences might affect the emergent functional impact of those vesicles on the ecosystem.

Metabolites. A combination of targeted and untargeted metabolomics analysis identified 1662 and 2035 unique mass features in vesicle populations from Prochlorococcus MIT9312 and MIT9313, respectively (Supporting Information Table S5). These mass features represented molecules across a range of $\mathrm{m} / \mathrm{z}$ values ( $\sim 94$ to $\sim 800$ ), polarities, and charge states (Supporting Information Table S6). Most vesicle-associated metabolites detected were non-polar (90\% and $85 \%$ in MIT9312 and MIT9313 vesicles, respectively), whereas non-polar metabolites represented $52 \%-56 \%$ of mass features detected in the cells (Tables S5 and S6). The identification of diverse non-polar molecules in vesicles further supports the idea that extracellular vesicles can serve as vehicles for the secretion of hydrophobic compounds (Mashburn and Whiteley, 2005; Schertzer et al., 2009), facilitating biological activities that depend on extracellular transport of nonpolar molecules within aqueous environments.

While we are not able to identify most of the observed mass features, we could document a number of known compounds within the vesicles (Table 2). For instance, vesicles from both strains contained phylloquinone (Vitamin K1), a compound involved in electron transfer. We also identified a number of oxidized carotenoid

Table 2. Non-intact polar lipid metabolites identified within Prochlorococcus vesicles.

\begin{tabular}{|c|c|c|c|c|c|c|c|}
\hline Compound name & Fraction & Compound class & $\begin{array}{l}\text { MIT9312 } \\
\text { vesicles }\end{array}$ & $\begin{array}{l}\text { MIT9313 } \\
\text { vesicles }\end{array}$ & $\begin{array}{l}\text { Confidence } \\
\text { level }\end{array}$ & $\mathrm{m} / \mathrm{z}$ & $\begin{array}{l}\text { RT } \\
(\min )\end{array}$ \\
\hline Triose & HILICAqNeg & Sugar & + & + & $3 a$ & 503.1629 & 13.6 \\
\hline Tetraose & HILICAqNeg & Sugar & + & + & 3a & 665.2164 & 14.4 \\
\hline $\begin{array}{l}\text { Phylloquinone (Vitamin } \\
\text { K1) }\end{array}$ & RPOrgPos & Electron transfer & + & + & 1 & 451.3572 & 14.6 \\
\hline Carotene & RPOrgPos & Pigment & + & + & 1 & 536.4371 & 16.1 \\
\hline Protoporphyrin & RPOrgPos & $\begin{array}{l}\text { Pigment or cyt-c } \\
\text { precursor }\end{array}$ & + & + & 2 & 563.2656 & 12.8 \\
\hline 1-Lauroyl-glycerol (C12) & RPOrgPos & Lipid & + & + & 2 & 257.2111 & 11.7 \\
\hline 1-Myristoyl-glycerol (C14) & RPOrgPos & Lipid & + & + & 2 & 285.2423 & 13.2 \\
\hline Beta-Apo-12'-carotenal & RPOrgPos & $\begin{array}{l}\text { Pigment oxidation } \\
\text { product }\end{array}$ & + & + & $3 b$ & 351.2682 & 13.5 \\
\hline Apo-12'-zeaxanthinal & RPOrgPos & $\begin{array}{l}\text { Pigment oxidation } \\
\text { product }\end{array}$ & + & + & $3 b$ & 367.2633 & 12.0 \\
\hline Beta-Apo-10'-carotenal & RPOrgPos & $\begin{array}{l}\text { Pigment oxidation } \\
\text { product }\end{array}$ & + & + & $3 b$ & 377.2839 & 13.8 \\
\hline Apo-10'-zeaxanthinal & RPOrgPos & $\begin{array}{l}\text { Pigment oxidation } \\
\text { product }\end{array}$ & + & + & $3 b$ & 393.2785 & 12.4 \\
\hline
\end{tabular}

For details on analytical fractions and confidence level assessments, see Methods and Supplementary Information. $+=$ detected. 
products (Table 2) in vesicles from both strains, though it is unclear whether these carotenoids were oxidized in the cell and then exported via vesicles or whether they became oxidized following vesicle release. Although we focused our analysis on the compounds present in vesicles, cellular compounds absent in vesicles are also of interest (Table S7). For example, Prochlorococcus cells contained potential osmolytes such as sucrose, glycine betaine, or glucosylglycerol, which help maintain cellular osmotic balance in cyanobacteria (Klähn and Hagemann, 2010), but these compounds were undetectable in either set of vesicles (Supporting Information Table S7). This represents a puzzle as to how cytoplasmic material could be exported to vesicles without including (or retaining) the most abundant solutes in the cell and raises questions concerning how vesicles may change in response to osmotic stresses.

\section{Nutrient and energy sources within vesicles}

Prochlorococcus vesicles have been shown to serve as sources of organic carbon and/or energy for supporting growth of co-cultured bacteria (Biller et al., 2014). Much of a vesicle's carbon and chemical energy content is found within the lipids, as each $100 \mathrm{~nm}$ diameter vesicle will contain $\sim 10000$ lipid molecules in its envelope. The diverse proteins and metabolites exported within vesicles represent potential labile organic carbon sources as well. In one notable example, vesicles from both strains contained triose and tetrose sugars (Table 2), which were not measurable above background levels within cells. While not the focus of this work, Prochlorococcus vesicles contain DNA and RNA (Biller et al., 2014) as well, and vesicle-associated nucleic acids may also function as an energy or nutrient source for microbes (Jørgensen and Jacobsen, 1996).

We previously observed nutrient binding proteins, such as those for urea, phosphate, and iron, in the vesicles exported by Prochlorococcus strains MED4 and MIT9313 (Biller et al., 2014). This suggested that vesicles might transport nutrients or even scavenge compounds as they diffuse through seawater and, in turn, organisms that encounter these vesicles could gain access to a locally concentrated 'packet' of nutrients. To continue to explore this hypothesis, we looked for annotated substrate-binding proteins and transporters in the proteome data. We again identified putative substrate-binding proteins (many associated with $A B C$ transporters) for urea, phosphate, and iron in the vesicles, along with those for manganese and amino acids (Supporting Information Tables S2 and S3). Vesicles produced by both strains contained putative transporters for sulfate, magnesium, and ammonium (Supporting Information Tables S2 and S3), raising the possibility that - assuming favourable energetics and proper protein orientation in the membrane - vesicles could accumulate these compounds following cellular release.

As a first step toward determining whether the nutrients that the proteomic data suggest might be transported by vesicles are actually present, we measured vesicle phosphate content and compared it with that of the average cell. Vesicles from MIT9312 and MIT9313 contained $3.4 \pm 3.2$ and $3.7 \pm 2.1$ femtomoles phosphate per $10^{6}$ vesicles, respectively. Given that a Prochlorococcus MED4 cell (similar in size to MIT9312) contains $\sim 10$ attomoles phosphorus (P) (Bertilsson et al., 2003) and Pelagibacter HTCC7211 cells contain $\sim 16$ attomoles $P$ (White et al., 2019) under P-limited conditions, an encounter with a single Prochlorococcus vesicle would supply only $\sim 0.01 \%$ of these cells' $P$ quota. These are averages, however, and absent an understanding of the distribution of $\mathrm{P}$ per vesicle and vesicle-cell encounter rates it is impossible to speculate further; we simply flag this as an interesting question to pursue. We also note that the presence of nucleic acids in vesicles represents a possible source of organic phosphorous.

As has been observed in gram-negative pathogens (Pérez-Cruz et al., 2015), vesicles from both Prochlorococcus strains contained ATP, with more released by MIT9312 than MIT9313 (c.f., $3.6 \pm 1.4 \times 10^{-3}$ and $0.13 \pm 0.097 \times 10^{-3}$ femtomoles ATP per $10^{6}$ vesicles, respectively). This has relevance for interpreting measurements of 'dissolved' ATP in the $<0.2 \mu \mathrm{m}$ fraction of seawater (Azam and Hodson, 1977) which we now know contains vesicles. This dissolved ATP can be utilized by marine microbes (Azam and Hodson, 1977) and has been proposed to arise largely from cellular excretion during active growth and/or grazing activity, as opposed to lysis of dead cells (Nawrocki and Karl, 1989; Björkman and Karl, 2001). Our results suggest that at least some fraction of this dissolved ATP excreted by marine microbes is likely associated with extracellular vesicles.

\section{Prochlorococcus vesicles contain catalytically active enzymes}

Many of the most abundant proteins in the vesicles were putative enzymes (Supporting Information Table S2) which have the potential to mediate exoenzymatic activities. We conducted a set of in vitro biochemical assays with intact, purified vesicles and showed that they exhibit lipase, phosphatase, protease, and sulfatase activity (Fig. 3). Vesicle-associated enzymes are thus able to access substrates in the media, likely either via leakage of compounds across the membrane, transport into the vesicle interior, or by acting directly on substrates outside of the vesicle. We also observed that substrate 

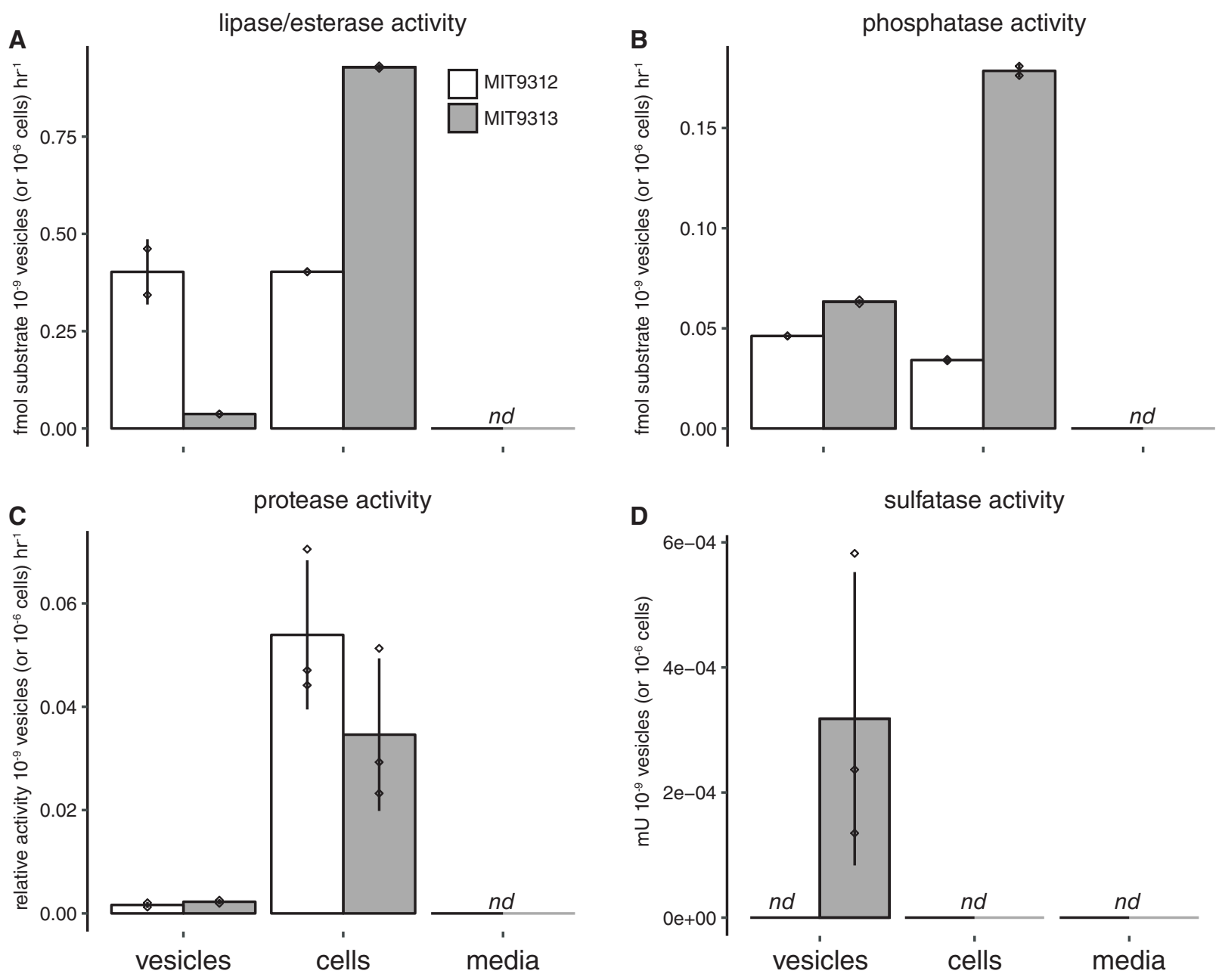

Fig. 3. Enzymatic activity in purified Prochlorococcus vesicles. Activity of (A) lipases, (B) phosphatases, (C) proteases, and (D) sulfatases in samples of vesicles from Prochlorococcus MIT9312 (white) and MIT9313 (grey) are compared to that of cells and media background. Values represent the mean $( \pm \mathrm{SD})$ of two to three biological replicates, standardized per population of either $10^{9}$ vesicles or $10^{6}$ cells. $n d=$ not detected.

accessibility can differ between vesicles and cells: Prochlorococcus MIT9313 vesicles displayed measurable sulfatase activity, while intact cells did not (Fig. 3D). Thus, vesicle-associated enzymes have the potential to act upon extracellular substrates that they might not encounter within the cell (Ebner and Götz, 2019), suggesting that many proteins typically thought to be cytosolic could contribute to extracellular biogeochemical processes in situ.

We speculate that exporting enzymes in vesicles could be a means of protecting the proteins from environmental damage and degradation, allow for simultaneous cosecretion of multiple proteins, and/or provide an environment where substrates could be maintained in close proximity in the otherwise dilute oligotrophic ocean (Bonnington and Kuehn, 2014). Given that osmolytes can play important roles in maintaining enzyme activity within cells (Yancey, 2005), it is also intriguing that these vesicle-associated enzyme activities are maintained in the absence of the most abundant detectable cellular osmolytes. While cyanobacteria and many other microbes specifically secrete certain exoenzymes into their local environment (Christie-Oleza et al., 2015), the broad diversity of the vesicle proteome seen here indicates that most cellular enzymes may be exported at some level within vesicles and thus have the potential to function extracellularly. Can marine extracellular vesicles interact with cells from
different organisms?

We know from studies of terrestrial and host-associated microbes that many biological functions of vesicles are attributable to the transfer of vesicle contents between cells (Schwechheimer and Kuehn, 2015; Brown 
et al., 2015). Vesicle-mediated biotic 'interactions' may encompass a range of mechanisms, from vesicleassociated activities occurring in proximity to a cell (e.g. enzymatic activities or phage defence; MacDonald and Kuehn, 2012; Biller et al., 2014; Rakoff-Nahoum et al., 2014) to the delivery of vesicle contents into another cell (Kadurugamuwa and Beveridge, 1999). To begin to explore interactions between Prochlorococcus vesicles and cells, we looked for physical associations between fluorescently labelled vesicles and six different marine microbes from the Proteobacteria, Cyanobacteria, and Bacteroidetes - the three most abundant bacterial phyla in the oceans (Fig. 4). We found that vesicles from Prochlorococcus MIT9313 associated with cells of both Prochlorococcus MIT9312 and MIT9313, along with representatives of the marine Gammaproteobacteria and Alphaproteobacteria - including Candidatus Pelagibacter ubique HTCC7211, a member of the numerically dominant SAR11 group of marine heterotrophs (Figs. 4 and S7). The breadth of interactions was not specific to Prochlorococcus vesicles, as vesicles purified from the marine heterotroph Alteromonas MIT1002, which was coisolated with Prochlorococcus (Biller et al., 2015b), were also able to interact with these strains (Figs. 4 and S7). To ensure that the observed vesicle-cell associations were not an artefact of the fluorescent dye used, we incubated the same set of marine microbes with vesicles from an E. coli strain (Dinh and Bernhardt, 2011) which instead expressed GFP within vesicles, and found that they were also able to interact with multiple microbes (Figs. 4B and S7). While we further verified that our fluorescent vesicle labelling approach did not significantly influence the ability of $E$. coli vesicles to interact with cells (Fig. S8), we cannot rule out a potential influence of vesicle surface modifications on the pairwise interactions tested.

Four of the strains examined interacted with all of the vesicles tested (Fig. 4B) while two others exhibited apparent specificity toward vesicles from different sources. That is, vesicles from both Alteromonas and Prochlorococcus MIT9312 did not associate with Prochlorococcus MIT9313 cells, and none of the vesicles interacted with Polaribacter MED152, a marine Bacteroidetes (González et al., 2008), at our detection levels (Fig. 4B). This confirms that our observations are not simply due to experimental conditions or random 'sticking' of vesicles to cells. Specificity in vesicle-cell associations has been shown in some heterotrophic bacteria (Tashiro et al., 2017; Toyofuku et al., 2017) and likely underlies variation in vesicle-mediated DNA transfer rates among species (Tran and Boedicker, 2017). Our data are consistent with the hypothesis that different vesicle-cell pairs may vary in the strength of their interactions (Supporting Information Fig. S7). For example, the propensity of a vesicle to associate with a particular cell may depend on its specific surface composition, which would likely be obscured by the averaging effect of our population-scale analysis. The apparent lack of vesicle associations with Polaribacter in our experiments is striking and invites an exploration of what factors, such as surface charge (Tashiro et al., 2017), cell envelope structure, and surface hydrophobicity (MacDonald and Beveridge, 2002),
A
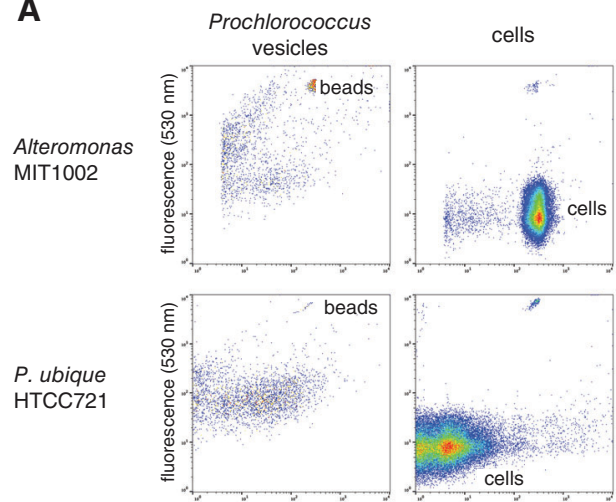

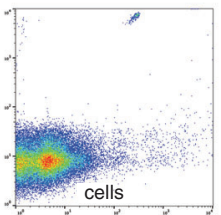

forward scatter (size)
cells+Prochlorococcus
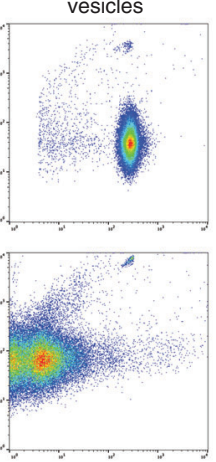

B

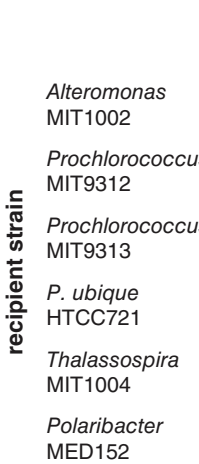

vesicle source

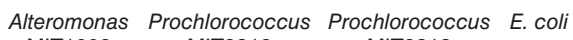
$\begin{array}{lll}\text { MIT1002 MIT9312 MIT9313 } & \end{array}$

\begin{tabular}{|c|c|c|c|}
\hline+ & + & + & + \\
\hline+ & + & + & + \\
\hline nd & nd & + & + \\
\hline+ & + & + & + \\
\hline+ & + & + & + \\
\hline nd & nd & nd & nd \\
\hline
\end{tabular}

Fig. 4. Association of extracellular vesicles with diverse microbial cells.

A. Example flow cytometry plots of fluorescently labelled Prochlorococcus MIT9313 vesicles (left), Alteromonas MIT1002 and Pelagibacter ubique (SAR11) cell populations (centre), and the same cells following a $2 \mathrm{~h}$ incubation with vesicles (right). Internal reference beads are labelled.

B. Interaction of labelled vesicles with cells $(+)$, or lack thereof ( $n d=$ not detected), for different 'source' strains (vesicle producers) and 'recipient' strains (cells exposed to labelled vesicles). Positive interactions were determined based on two criteria: an increase in normalized median cellular $530 \mathrm{~nm}$ fluorescence when mixed with labelled vesicles (as in a; see also Fig. S7), and a statistically significant shift in the cellular population distribution $\left(\chi^{2} \mathrm{~T}(\mathrm{x})\right.$ test, $P<0.01$ in two to three biological replicates; see Supplementary Methods). Alteromonas and Prochlorococcus vesicles were covalently labelled with an amine-reactive Alexa 488 dye; E. coli vesicles contained GFP. 
might define interaction boundaries. More generally, these results raise new questions concerning the degree to which vesicles should be considered 'public goods' in the oceans.

The vesicle-cell associations could be disrupted by repeated rounds of centrifugation and washing of the cells (Supporting Information Fig. S9), suggesting that the majority of labelled vesicle material was not fully integrated into the outer membrane of the cells (at least at this timepoint) but was attached via non-covalent bonding between the two surfaces. Although these observations do not directly establish a particular biologically relevant function, we speculate that 'captured' vesicles could serve many functions, including delivering cargo through membrane fusion, 'flipping' of molecules from the vesicle membrane into the cell (Remis et al., 2014), or extracellular degradation and subsequent uptake of vesicle contents. Alternatively, the presence of vesicles nearby could serve defensive roles for cells (Manning and Kuehn, 2011) or influence cellular processes via enzymatic activities.

\section{Potential functional roles for Prochlorococcus vesicles in marine ecosystems}

The diversity of extracellular vesicle contents observed here is consistent with the idea that vesicles do not have one dedicated function but instead may play a variety of roles within microbial ecosystems. Our detailed inventory of Prochlorococcus extracellular vesicle contents indicates potential functional impacts of vesicles specific to dilute ocean ecosystems that merit future exploration from both conceptual and quantitative perspectives. There are a broad range of compounds within vesicles that could be exchanged between microbes or serve other roles in these particular ecosystems. For instance, the triose and tetrose sugars could serve as an additional energy or carbon source for organisms, act as antioxidants, or possibly serve as the primary osmolyte within vesicles (Goh et al., 2010). While there may be only $\sim 2$ molecules of ATP within any individual vesicle on a bulkaverage basis, the aggregate impact of vesicleassociated ATP exchange among cells remains to be established; further, the presence of proteins and ATP within the same vesicle could facilitate ATP-requiring extracellular reactions or enable other types of roles such as signalling. Many additional possible ecological functions for vesicles are likely reflected in the other proteins and metabolites found in our inventory of Prochlorococcus vesicles, which we have not specifically discussed here.

The identification of diverse oxidized compounds in Prochlorococcus vesicles (Table 2 and Fig. 1D) raises additional questions concerning the role vesicles may play in dissipating oxidative stress - a particular challenge for Prochlorococcus, which lacks enzymes typically used for detoxification of hydrogen peroxide such as catalase (Scanlan et al., 2009). Vesicles could be acting as a mechanism for removing damaged compounds, complementing other cellular metabolite degradation and repair pathways (Linster et al., 2013), or as a 'sink' for reactive oxygen species (ROS) generated within the cell, within vesicles, or in the extracellular seawater environment (Morris et al., 2016). Regardless of the oxidative mechanism(s) involved, suppression of ROS toxicity and/or removal of oxidized metabolites may be another way in which vesicles serve a protective role for cells (Manning and Kuehn, 2011). Our identification of vesicleassociated carotenoids, which have also been observed in vesicles from Synechocystis PCC6803 (Pardo et al., 2015), raise broader questions as to whether these compounds might serve a photoprotective role for vesicle contents.

Given the number of proteins and small molecules identified in the vesicles, it seems implausible that these materials are uniformly distributed among each member of the vesicle population. We have previously shown heterogeneity of DNA fragment incorporation into vesicles from multiple marine bacteria (Biller et al., 2017), and vesicle subpopulations containing both outer and inner membrane material from Gram-negative cells have been reported (Pérez-Cruz et al., 2015). Furthermore, distinct vesicle subpopulations with unique origins and epitopes have been noted for some time in eukaryotic cells (Kowal et al., 2016). Thus, the functional potential of one vesicle is likely different from the next - similar to our perspective on the cells from which vesicles are derived, whose ecological role can only be understood by viewing them as populations of diverse entities, which may display a diverse range of functions in different contexts (Biller et al., 2015a).

\section{Conclusions}

The abundance of vesicles in seawater, and the diversity of their chemical contents, prompt a reassessment of how we conceptualize and interpret the pool of dissolved organic matter that is so critical to the function of marine ecosystems. While many cellular compounds are secreted in the form of truly 'dissolved' individual molecules, it is now clear that microbes also release organic molecules in locally structured, colloidal vesicles which may influence the accessibility, activity, and half-lives of their contents. As such, vesicles blur the boundaries between definitions of 'particulate' and 'dissolved', or 'living' and 'detrital', in marine biogeochemistry - distinctions that are critical for understanding and modelling the system. Extracellular vesicles represent a new frontier for 
understanding the flow of energy, materials, and information in ocean ecosystems.

\section{Experimental procedures}

Culturing conditions and sampling for lipidomics, proteomics, and metabolomics

To minimize media background signals, axenic cultures of Prochlorococcus MIT9312 and MIT9313 used for lipidomics, proteomics, and metabolomics analyses were grown in chemically defined artificial AMP1 media (Moore et al., 2007) supplemented with $10 \mathrm{mM}$ (final concentration) filter-sterilized sodium bicarbonate. All 20 I cultures were grown in polycarbonate carboys (ThermoFisher Nalgene, Waltham, MA, USA) with gentle stiring (60 rpm), under constant light flux $(10-20 \mu \mathrm{mol} Q$ $\mathrm{m}^{-2} \mathrm{~s}^{-1}$ for MIT9313; 30-40 $\mu \mathrm{mol} Q \mathrm{~m}^{-2} \mathrm{~s}^{-1}$ for MIT9312) at $24^{\circ} \mathrm{C}$.

All cell and vesicle samples were collected during midto-late exponential growth phase. Cell pellets were obtained by gently centrifuging cells $(7500 \times g)$ for $10 \mathrm{~min}$ at $4^{\circ} \mathrm{C}$; vesicle isolation is detailed below. For lipidomics, proteomics, and metabolomics analyses, a total of seven $20 \mathrm{I}$ cultures were grown in AMP1 media for each of the two Prochlorococcus strains, providing three replicates for the lipid and small metabolite analysis and an additional sample for proteomics analysis. Prochlorococcus AMP1 growth media blanks and vesicle suspension buffer [phosphate buffered saline (PBS)] blanks served as controls for lipidomics, proteomics, and metabolomics analysis; they were extracted and analysed alongside all cell and vesicle samples. Since Prochlorococcus was grown under continuous light, the cultures were not synchronized. Thus, all cell samples represent a bulk average population of cells at all stages of the cell cycle; vesicle samples similarly integrate material released across both the lag and exponential growth (steady state) phases.

\section{Vesicle isolation}

Vesicles were isolated as described previously (Biller et al., 2014). Briefly, cultures were first gravity filtered through a $0.2 \mu \mathrm{m}$ capsule filter (Polycap 150TC; GE Life Sciences/Whatman, Maidstone, UK). The filtrate was then concentrated using a $100 \mathrm{kDa}$ tangential flow filter (Ultrasette with Omega membrane; Pall, Port Washington, NY, USA) and re-filtered through a $0.2 \mu \mathrm{m}$ syringe filter. Vesicles were pelleted from the sample by ultracentrifugation at $\sim 100000 \times g$ (Beckman-coulter SW32Ti rotor; $32000 \mathrm{rpm}, 1.5 \mathrm{~h}, 4^{\circ} \mathrm{C}$ ), purified on an OptiPrep gradient (Biller et al., 2014), then washed and resuspended in $0.2 \mu \mathrm{m}$ filtered $1 \times$ PBS.
Vesicle concentrations were measured with a NanoSight LM10HS instrument equipped with a LM14 blue laser module using NTA software V3.1 (NanoSight/ Malvern, Westborough, MA, USA). Samples were diluted such that the average number of particles per field was between 20 and 60, per the manufacturer's guidelines. Three replicate videos were collected from each sample at a camera level of 11 and analysed at a detection threshold of 1 . The sample chamber was thoroughly flushed with $18.2 \mathrm{M} \Omega \mathrm{cm}^{-1}$ water (Milli-Q; Millipore, Burlington, MA, USA) between samples and visually examined to ensure that no particles were carried over.

\section{Lipidomics}

Lipids were extracted from triplicate cell pellets and vesicles from Prochlorococcus MIT9312 or MIT9313 using a modified Bligh and Dyer protocol using a 2:1:0.8 ratio of methanol:dichloromethane:phosphate buffered saline (Popendorf et al., 2013). The total lipid extract was analysed on an Agilent 1200 reversed phase highperformance liquid chromatograph (HPLC) coupled to a ThermoFisher Exactive Plus Orbitrap high-resolution mass spectrometer (HRMS; ThermoFisher, Waltham, MA, USA) which scanned across a range of 100$1500 \mathrm{~m} / \mathrm{z}$. HPLC and MS conditions are based on methods described by Collins et al., 2016 (modified after Hummel et al., 2011) and are detailed in the Supporting Information. For the identification and peak area integration, we used LOBSTAHS, an open-source lipidomics software workflow based on adduct ion abundances and several other orthogonal criteria (Collins et al., 2016). Lipid peaks identified using the LOBSTAHS software were integrated from MS data after pre-processing with XCMS (Smith et al., 2006) and CAMERA (Kuhl et al., 2012) and corrected for differences in response factors among different lipids using commercially available standards as described by Becker et al. (2018). Additional details are available in the Supplementary Information.

\section{Proteomics}

Proteins were extracted from cell biomass and vesicles from a single $20 \mathrm{I}$ batch culture of Prochlorococcus MIT9313 or MIT9312. Filters containing cell biomass or vesicle suspensions were extracted using bead-beating and freeze-thaw cycles. Proteins from lysed cells or vesicles were suspended in RapiGest SF (Waters, Milford, MA, USA) to facilitate protein solubilization and then underwent disulfide reduction with tris(2-carboxyethyl)phosphine, alkylation with iodoacetamide, and in-solution protease digestion using either a trypsin/Lys-C mix or Glu-C (Promega, Madison, WI, USA). Following RapiGest hydrolysis and 
desalting, samples were resuspended in a solution containing an internal standard of synthetic peptides (Hi3 Escherichia coli standard, Waters), spiked with iRT retention time standard (Biognosys, Boston, MA, USA), and immediately analysed on a Waters ACQUITY M-class LC coupled to a Thermo QExactive HF HRMS equipped with a nano-electrospray source. Data-dependent acquisition was performed on the top 10 ions and data analysis were conducted using the software from the trans-proteomic pipeline (TPP v.5.1.0) (Nesvizhskii et al., 2007).

Label-free comparison of relative protein abundances was facilitated by normalizing protein spectral counts to the Hi3 internal standard to account for differences in ionization of peptides due to sample matrix affects and then normalizing to the amount of biomass injected onto the LC-HRMS. To compare protein enrichments within Prochlorococcus cell and vesicle fractions, 'per cell' or 'per vesicle' spectral counts were then normalized on the basis of size, or biovolume, differences between a cell and a vesicle, herein referred to as 'biovolumenormalized protein spectral counts' (Supporting Information Tables S2 and S3). Unless otherwise indicated, proteome comparisons across cells and vesicles were conducted using biovolume-normalized spectral counts from only trypsin/Lys-C-based proteomes (Fig. 2). Relative protein enrichments in Prochlorococcus vesicles as compared with cells was computed using $\log _{2}$ ratios (Supporting Information Table S4) and displayed in Fig. 2A using only the proteins with spectral counts in the top $25 \%$ of those identified in vesicles of strain MIT9312 or MIT9313. Subcellular localization assignments are based on a combination of predictions from the Uniprot database (https://www.uniprot.org), results from the PSORTb algorithm (V3.0.2) (Yu et al., 2010), amended with data from TMHMM 2.0 (Krogh et al., 2001) and SignalP (V4.1) (Nielsen, 2017), based on the Gramnegative bacteria model. Proteins with a putative signal peptide but no other significant localization predictions are noted as being 'unclassified non-cytoplasmic'. Additional details are available in Supplementary Information.

\section{Metabolomics}

Cell pellets and vesicles originating from triplicate $20 \mathrm{I}$ batch cultures of Prochlorococcus MIT9312 or MIT9313 were extracted using a modified Bligh and Dyer technique with cold 1:1 methanol/water (aqueous phase) and cold dichloromethane (organic phase) (Bligh and Dyer, 1959; Boysen et al., 2018). Cell pellets were manually disrupted by bead beating during the extraction, as described by Boysen et al. (2018); vesicles were extracted without bead beating. Metabolite separations were achieved using reversed-phase (RP, for aqueous and organic extracts) and hydrophilic interaction liquid chromatography (HILIC, for aqueous extracts only), as detailed in Table S8 and Boysen et al., 2018. Data were collected in positive ion mode for RP analyses with a scan range of $90-900 \mathrm{~m} / \mathrm{z}$. For HILIC analyses, data were obtained in positive and negative mode (using polarity switching) with a scan range of $80-900 \mathrm{~m} / \mathrm{z}$. For every sample, data were processed in four subgroups, defined by phase, chromatography, and ion mode: RPorganic-positive (RPOrgPos), RP-aqueous-positive (RPAqPos), HILIC-aqueous-positive (HILICAqPos), and HILIC-aqueous-negative (HILICAqNeg). Data were collected using Thermo QExactive HF HRMS using same settings as in the study by Boysen et al. (2018).

For targeted data, individual metabolite features were integrated using Skyline Daily (MacLean et al., 2010) and subjected to an in-house quality control protocol (Boysen et al., 2018). Untargeted data were processed using MSDIAL software (Tsugawa et al., 2015) using parameters reported in Table S9. MS-DIAL was used to pick, align, and integrate mass features from raw datasets. Identification of mass features within untargeted data sets was accomplished via dereplication of the mass feature list against several databases, yielding identifications of variable confidence as described in the study by Heal et al. (2019). We ranked confidence in mass feature identifications according to existing literature (Sumner et al., 2007). All mass features were searched against an Ingalls Lab in-house database of authenticated standards, LOBSTAHs output, and MassBank (Horai et al., 2010). Additional details are available in Supplementary Information.

\section{Vesicle enzyme activity assays}

All nutrient and enzymatic assays were carried out using vesicles collected from $20 \mathrm{I}$ exponentially growing Prochlorococcus cultures grown as above. Vesicles were purified using an OptiPrep (lodixanol) density gradient as described in the study by Biller et al. (2014) and washed in clean $1 \times$ PBS. ATP was measured using a standard luminescence-based assay with the BacTiter-Glo kit (Promega) according to the manufacturer's directions. Vesicle phosphate was measured using the SigmaAldrich Phosphate Assay kit (MilliporeSigma, St. Louis, $\mathrm{MO}$, USA). Protease measurements were made using the Sigma-Aldrich Protease Fluorescent Detection Kit following the manufacturer's instructions with the following modifications: $10 \mu$ of a $2 \times$ incubation buffer was used in each $50 \mu \mathrm{l}$ reaction, which allowed us to add $20 \mu \mathrm{l}$ of sample to each reaction and increase the number of vesicles included in the reaction. The reaction was carried out for $18-20 \mathrm{~h}$ at $28^{\circ} \mathrm{C}$ in the dark. Sulfatase activity was measured using the BioVision Sulfatase Activity Assay (BioVision, Milpitas, CA, USA), following manufacturer's instructions. 
Phosphatase and lipase activity were measured by following the hydrolysis of fluorescent substrates 4-methylumbelliferyl phosphate and 4-methylumbelliferyl oleate (both from Sigma-Aldrich) following standard methods (Hoppe, 1993). Briefly, $\sim 10^{10}$ vesicles in $1 \times$ PBS were incubated with $100 \mu \mathrm{M}$ substrate (dissolved in ethylene glycol monomethyl ether) and natural seawater from the Sargasso Sea in a $200 \mu \mathrm{l}$ reaction within a black-walled 96-well plate at room temperature for $16 \mathrm{~h}$. Boiled vesicle samples and substrate in seawater lacking any added vesicles were used as controls.

\section{Vesicle interaction experiments}

All cultures used for the interaction experiments were grown in media based on $0.2 \mu \mathrm{m}$ filtered natural water from Vineyard Sound, MA except where noted. Vesicles were purified from $20 \mathrm{I}$ cultures of Prochlorococcus MIT9312 or MIT9313 grown as above but in Pro99 media (Moore et al., 2007), and 10 I cultures of Alteromonas strain MIT1002 (Biller et al., 2015b) were grown at $24^{\circ} \mathrm{C}$ in ProMM media (Berube et al., 2015) (Pro99 media, as above, plus lactate, pyruvate, glycerol, acetate, and $1 \times$ Va vitamin mix; Waterbury and Willey, 1988). The $10 \mathrm{I}$ cultures of E. coli strain TB28(attHKTB263) (Dinh and Bernhardt, 2011; this strain expresses the Superfolder variant of GFP and targets it to the periplasm) were grown at $30^{\circ} \mathrm{C}$ in $\mathrm{M} 9$ maltose media supplemented with $250 \mu \mathrm{M}$ isopropyl $\beta$-D-1-thiogalactopyranoside and $100 \mathrm{~g} \mathrm{~m} \mathrm{~m}^{-1}$ ampicillin. Purified vesicles were covalently labelled with an amine-reactive Alexa Fluor 488 5-SDP ester dye (Molecular Probes/ThermoScientific).

To examine the ability of vesicles to associate with representative phylogenetically distinct marine microbes, cells of Prochlorococcus MIT9312 and MIT9313 (in Pro99 media), Alteromonas MIT1002 and Thalassospira MIT1004 (Biller et al., 2017) (in ProMM media), and Polaribacter MED152 (González et al., 2008) (in Pro99 media, supplemented with $5 \mathrm{~g}$ I peptone and $1 \mathrm{~g}$ I yeast extract) were all grown to mid-exponential growth phase at $24^{\circ} \mathrm{C}$. Pelagibacter HTCC7211 was grown in defined AMS1 media (Carini et al., 2013) at $22^{\circ} \mathrm{C}$. Approximately $10^{9}-10^{10}$ vesicles (labelled or unlabelled), or an equivalent volume of the PBS Alexa 488 labelling control, were added

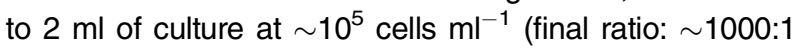
vesicles:cells). Cultures with vesicles were incubated for $2 \mathrm{~h}$ at the normal growth temperatures and examined on an Influx flow cytometer (Cytopeia/BD, Franklin Lakes, $\mathrm{NJ}$ ). Cells were excited using a blue $488 \mathrm{~nm}$ laser and monitored for chlorophyll (692/40 nm emission) and Alexa 488/GFP (530/40 nm emission) fluorescence. All flow cytometry data were analysed using FlowJo (V10.5). Additional details are available in Supplementary Information.

\section{Miscellaneous}

All data were analysed in R (V3.5.1). Plots were created using ggplot2 (Wickham, 2009).

\section{Data availability}

The mass spectrometry proteomics data have been deposited to the ProteomeXchange Consortium via the PRIDE (Perez-Riverol et al., 2019) partner repository with the dataset identifier PXD013602. Metabolite data are available at the NIH Common Fund's National Metabolomics Data Repository (NMDR) website, the Metabolomics Workbench, https://www.metabolomicsworkbench.org (Sud et al., 2016), under Study ID \# ST001524.

\section{Acknowledgements}

This work was funded by grants from the National Science Foundation (OCE-1356460 to S.W.C.) and the Simons Foundation (SCOPE Award ID 329108 to B.A.S.V.M., A.E.I., S.W.C.; Life Sciences Project Award ID 337262, S.W.C.; Simons Award ID 385428 to A.E.I. and 598819 to K.R.H.). K.W.B was supported by the Postdoctoral Scholarship Programme at the Woods Hole Oceanographic Institution. R.A.L was partially supported by a postdoctoral fellowship from the Swiss National Science Foundation. The authors thank Thomas Bernhardt (Harvard Medical School) for providing the sfGFP-expressing E. coli strain, Jarone Pinhassi (Linnaeus U.) for sharing Polaribacter MED152, and Stephen Giovannoni (U. Oregon) for Pelagibacter HTCC7211. The authors also thank Daniel Sher (U. Haifa) for providing helpful suggestions on the manuscript.

\section{References}

Azam, F., and Hodson, R.E. (1977) Dissolved ATP in the sea and its utilisation by marine bacteria. Nature 267: 696-698.

Becker, J.W., Hogle, S.L., Rosendo, K., and Chisholm, S.W. (2019) Co-culture and biogeography of Prochlorococcus and SAR11. ISME J 13: 1506-1519.

Becker, K.W., Collins, J.R., Durham, B.P., Groussman, R.D., White, A.E., Fredricks, H.F., et al. (2018) Daily changes in phytoplankton lipidomes reveal mechanisms of energy storage in the open ocean. Nat Commun 9: 5179.

Bertilsson, S., Berglund, O., Karl, D., and Chisholm, S. (2003) Elemental composition of marine Prochlorococcus and Synechococcus: implications for the ecological stoichiometry of the sea. Limnol Oceanogr 48: 1721-1731.

Bertilsson, S., Berglund, O., Pullin, M., and Chisholm, S. (2005) Release of dissolved organic matter by Prochlorococcus. Vie et Milieu 55: 225-232.

Berube, P.M., Biller, S.J., Kent, A.G., Berta-Thompson, J.W., Roggensack, S.E., Roache-Johnson, K.H., et al. (2015) Physiology and evolution of nitrate acquisition in Prochlorococcus. ISME J 9: 1195-1207. 
Biller, S.J., Berube, P.M., Lindell, D., and Chisholm, S.W. (2015a) Prochlorococcus: the structure and function of collective diversity. Nat Rev Microbiol 13: 13-27.

Biller, S.J., Coe, A., Martin-Cuadrado, A.-B., and Chisholm, S.W. (2015b) Draft genome sequence of Alteromonas macleodii strain MIT1002, isolated from an enrichment culture of the marine cyanobacterium Prochlorococcus. Genome Announc 3: e00967-e00915.

Biller, S.J., McDaniel, L.D., Breitbart, M., Rogers, E., Paul, J. H., and Chisholm, S.W. (2017) Membrane vesicles in sea water: heterogeneous DNA content and implications for viral abundance estimates. ISME J 11: 394-404.

Biller, S.J., Schubotz, F., Roggensack, S.E., Thompson, A. W., Summons, R.E., and Chisholm, S.W. (2014) Bacterial vesicles in marine ecosystems. Science 343: 183-186.

Bitto, N.J., Cheng, L., Johnston, E.L., Pathirana, R., Phan, T. K., Poon, I.K.H., et al. (2021) Staphylococcus aureus membrane vesicles contain immunostimulatory DNA, RNA and peptidoglycan that activate innate immune receptors and induce autophagy. J Extracell Vesicles 10: e12080.

Björkman, K.M., and Karl, D.M. (2001) A novel method for the measurement of dissolved adenosine and guanosine triphosphate in aquatic habitats: applications to marine microbial ecology. J Microbiol Methods 47: 159-167.

Bligh, E.G., and Dyer, W.J. (1959) A rapid method of total lipid extraction and purification. Can $J$ Biochem Physiol 37: 911-917.

Bonnington, K.E., and Kuehn, M.J. (2014) Protein selection and export via outer membrane vesicles. Biochim Biophys Acta 1843: 1612-1619.

Boysen, A.K., Heal, K.R., Carlson, L.T., and Ingalls, A.E. (2018) Best-matched internal standard normalization in liquid chromatography-mass spectrometry metabolomics applied to environmental samples. Anal Chem 90: 1363-1369.

Brown, L., Wolf, J.M., Prados-Rosales, R., and Casadevall, A. (2015) Through the wall: extracellular vesicles in Gram-positive bacteria, mycobacteria and fungi. Nat Rev Microbiol 13: 620-630.

Carini, P., Steindler, L., Beszteri, S., and Giovannoni, S.J. (2013) Nutrient requirements for growth of the extreme oligotroph "Candidatus Pelagibacter ubique" HTCC1062 on a defined medium. ISME J 7: 592-602.

Christie-Oleza, J.A., Armengaud, J., Guerin, P., and Scanlan, D.J. (2015) Functional distinctness in the exoproteomes of marine Synechococcus. Environ Microbiol 17: 3781-3794.

Collins, J.R., Edwards, B.R., Fredricks, H.F., and Van Mooy, B.A.S. (2016) LOBSTAHS: an adduct-based lipidomics strategy for discovery and identification of oxidative stress biomarkers. Anal Chem 88: 7154-7162.

Cubillos-Ruiz, A., Berta-Thompson, J.W., Becker, J.W., van der Donk, W.A., and Chisholm, S.W. (2017) Evolutionary radiation of lanthipeptides in marine cyanobacteria. Proc Natl Acad Sci 114: E5424-E5433.

Deatherage, B.L., and Cookson, B.T. (2012) Membrane vesicle release in Bacteria, Eukaryotes, and Archaea: a conserved yet underappreciated aspect of microbial life. Infect Immun 80: 1948-1957.

Dinh, T., and Bernhardt, T.G. (2011) Using Superfolder green fluorescent protein for periplasmic protein localization studies. J Bacteriol 193: 4984-4987.
Ebner, P., and Götz, F. (2019) Bacterial excretion of cytoplasmic proteins (ECP): occurrence, mechanism, and function. Trends Microbiol 27: 176-187.

Flombaum, P., Gallegos, J.L., Gordillo, R.A., Rincón, J., Zabala, L.L., Jiao, N., et al. (2013) Present and future global distributions of the marine cyanobacteria Prochlorococcus and Synechococcus. Proc Natl Acad Sci 110: 9824-9829.

Goh, F., Barrow, K.D., Burns, B.P., and Neilan, B.A. (2010) Identification and regulation of novel compatible solutes from hypersaline stromatolite-associated cyanobacteria. Arch Microbiol 192: 1031-1038.

González, J.M., Fernandez-Gomez, B., FernàndezGuerra, A., Gómez-Consarnau, L., Sánchez, O., CollLladó, M., et al. (2008) Genome analysis of the proteorhodopsin-containing marine bacterium Polaribacter sp. MED152 (Flavobacteria). Proc Natl Acad Sci 105: 8724-8729.

Guerrero-Mandujano, A., Hernández-Cortez, C., Ibarra, J.A., and Castro-Escarpulli, G. (2017) The outer membrane vesicles: secretion system type zero. Traffic 18: 425-432.

Heal, K.R., Kellogg, N.A., Carlson, L.T., Lionheart, R.M., and Ingalls, A.E. (2019) Metabolic consequences of cobalamin scarcity in the diatom Thalassiosira pseudonana as revealed through metabolomics. Protist 170: 328-348.

Hoppe, H.-G. (1993) . In Use of Fluorogenic Model Substrates for Extracellular Enzyme Activity (EEA) Measurement of Bacteria. In Handbook of Methods in Aquatic Microbial Ecology, Kemp, P.F., Sherr, B.F., Sherr, E.B., and Cole, J.J. (eds). Boca Raton, FL: Lewis Publishers, pp. 423-431.

Horai, H., Arita, M., Kanaya, S., Nihei, Y., Ikeda, T., Suwa, K., et al. (2010) MassBank: a public repository for sharing mass spectral data for life sciences. J Mass Spectrom 45: 703-714.

Hummel, J., Segu, S., Li, Y., Irgang, S., Jueppner, J., and Giavalisco, P. (2011) Ultra performance liquid chromatography and high resolution mass spectrometry for the analysis of plant lipids. Front Plant Sci 2: 54.

Jørgensen, N.O., and Jacobsen, C.S. (1996) Bacterial uptake and utilization of dissolved DNA. Aquat Microb Ecol 11: 263-270.

Jürgens, U.J., and Weckesser, J. (1985) Carotenoidcontaining outer membrane of Synechocystis sp. strain PCC6714. J Bacteriol 164: 384-389.

Kadurugamuwa, J.L., and Beveridge, T.J. (1996) Bacteriolytic effect of membrane vesicles from Pseudomonas aeruginosa on other bacteria including pathogens: conceptually new antibiotics. J Bacteriol 178: 2767-2774.

Kadurugamuwa, J.L., and Beveridge, T.J. (1999) Membrane vesicles derived from Pseudomonas aeruginosa and Shigella flexneri can be integrated into the surfaces of other gram-negative bacteria. Microbiology 145: 2051-2060.

Klähn, S., and Hagemann, M. (2010) Compatible solute biosynthesis in cyanobacteria. Environ Microbiol 13: 551-562.

Kowal, J., Arras, G., Colombo, M., Jouve, M., Morath, J.P., Primdal-Bengtson, B., et al. (2016) Proteomic comparison defines novel markers to characterize heterogeneous populations of extracellular vesicle subtypes. Proc Natl Acad Sci 113: E968-E977. 
Krogh, A., Larsson, B., von Heijne, G., and Sonnhammer, E. L. (2001) Predicting transmembrane protein topology with a hidden Markov model: application to complete genomes. $J$ Mol Biol 305: 567-580.

Kuhl, C., Tautenhahn, R., Böttcher, C., Larson, T.R., and Neumann, S. (2012) CAMERA: an integrated strategy for compound spectra extraction and annotation of liquid chromatography/mass spectrometry data sets. Anal Chem 84: 283-289.

Li, B., Sher, D., Kelly, L., Shi, Y., Huang, K., Knerr, P.J., et al. (2010) Catalytic promiscuity in the biosynthesis of cyclic peptide secondary metabolites in planktonic marine cyanobacteria. Proc Natl Acad Sci U S A 107: 1043010435.

Linster, C.L., Van Schaftingen, E., and Hanson, A.D. (2013) Metabolite damage and its repair or pre-emption. Nat Chem Biol 9: 72-80.

Lynch, J.B., and Alegado, R.A. (2017) Spheres of hope, packets of doom: the good and bad of outer membrane vesicles in interspecies and ecological dynamics. $J$ Bacteriol 199: e00012-e00017.

MacDonald, I.A., and Kuehn, M.J. (2012) Offense and defense: microbial membrane vesicles play both ways. Res Microbiol 163: 607-618.

MacDonald, I.A., and Kuehn, M.J. (2013) Stress-induced outer membrane vesicle production by Pseudomonas aeruginosa. J Bacteriol 195: 2971-2981.

MacDonald, K.L., and Beveridge, T.J. (2002) Bactericidal effect of gentamicin-induced membrane vesicles derived from Pseudomonas aeruginosa PAO1 on gram-positive bacteria. Can J Microbiol 48: 810-820.

MacLean, B., Tomazela, D.M., Shulman, N., Chambers, M., Finney, G.L., Frewen, B., et al. (2010) Skyline: an open source document editor for creating and analyzing targeted proteomics experiments. Bioinformatics 26: 966-968.

Manning, A.J., and Kuehn, M.J. (2011) Contribution of bacterial outer membrane vesicles to innate bacterial defense. BMC Microbiol 11: 258.

Mashburn, L.M., and Whiteley, M. (2005) Membrane vesicles traffic signals and facilitate group activities in a prokaryote. Nature 437: 422-425.

Mashburn-Warren, L.M., and Whiteley, M. (2006) Special delivery: vesicle trafficking in prokaryotes. Mol Microbiol 61: 839-846.

Moore, L., Coe, A., Zinser, E.R., Saito, M., Sullivan, M., Lindell, D., et al. (2007) Culturing the marine cyanobacterium Prochlorococcus. Limnol Oceanogr: Methods 5: 353-362.

Morris, J.J., Johnson, Z.I., Wilhelm, S.W., and Zinser, E.R. (2016) Diel regulation of hydrogen peroxide defenses by open ocean microbial communities. J Plankton Res 38: 1103-1114.

Nawrocki, M.P., and Karl, D. (1989) Dissolved ATP turnover in the Bransfield Strait, Antarctica during a spring bloom. Mar Ecol Prog Ser 57: 35-44.

Nesvizhskii, A.I., Vitek, O., and Aebersold, R. (2007) Analysis and validation of proteomic data generated by tandem mass spectrometry. Nat Methods 4: 787-797.

Nielsen, H. (2017) Predicting secretory proteins with SignalP. Methods Mol Biol 1611: 59-73.
Orench-Rivera, N., and Kuehn, M.J. (2016) Environmentally controlled bacterial vesicle-mediated export. Cell Microbiol 18: $1525-1536$.

Ottesen, E.A., Young, C.R., Gifford, S.M., Eppley, J.M., Marin, R., Schuster, S.C., et al. (2014) Multispecies diel transcriptional oscillations in open ocean heterotrophic bacterial assemblages. Science 345: 207-212.

Pardo, Y.A., Florez, C., Baker, K.M., Schertzer, J.W., and Mahler, G.J. (2015) Detection of outer membrane vesicles in Synechocystis PCC 6803. FEMS Microbiol Lett 362: fnv163.

Pérez-Cruz, C., Delgado, L., López-Iglesias, C., and Mercade, E. (2015) Outer-inner membrane vesicles naturally secreted by Gram-negative pathogenic bacteria. PLOS ONE 10: e0116896.

Perez-Riverol, Y., Csordas, A., Bai, J., Bernal-Llinares, M., Hewapathirana, S., Kundu, D.J., et al. (2019) The PRIDE database and related tools and resources in 2019: improving support for quantification data. Nucleic Acids Res 47: D442-D450.

Popendorf, K.J., Fredricks, H.F., and Van Mooy, B.A.S. (2013) Molecular ion-independent quantification of polar glycerolipid classes in marine plankton using triple quadrupole MS. Lipids 48: 185-195.

Rakoff-Nahoum, S., Coyne, M.J., and Comstock, L.E. (2014) An ecological network of polysaccharide utilization among human intestinal symbionts. Curr Biol 24: 40-49.

Remis, J.P., Wei, D., Gorur, A., Zemla, M., Haraga, J., Allen, S., et al. (2014) Bacterial social networks: structure and composition of Myxococcus xanthus outer membrane vesicle chains. Environ Microbiol 16: 598-610.

Rontani, J.-F., and Belt, S.T. (2020) Photo- and autoxidation of unsaturated algal lipids in the marine environment: an overview of processes, their potential tracers, and limitations. Org Geochem 139: 103941.

Scanlan, D.J., Ostrowski, M., Mazard, S., Dufresne, A., Garczarek, L., Hess, W.R., et al. (2009) Ecological genomics of marine picocyanobacteria. Microbiol Mol Biol Rev 73: 249-299.

Schatz, D., Rosenwasser, S., Malitsky, S., Wolf, S.G., Feldmesser, E., and Vardi, A. (2017) Communication via extracellular vesicles enhances viral infection of a cosmopolitan alga. Nat Microbiol 2: 1485-1492.

Schertzer, J.W., Boulette, M.L., and Whiteley, M. (2009) More than a signal: non-signaling properties of quorum sensing molecules. Trends Microbiol 17: 189-195.

Schmidt, W., Drews, G., Weckesser, J., Fromme, I., and Borowiak, D. (1980) Characterization of the lipopolysaccharides from eight strains of the cyanobacterium Synechococcus. Arch Microbiol 127: 209-215.

Schwechheimer, C., and Kuehn, M.J. (2015) Outermembrane vesicles from Gram-negative bacteria: biogenesis and functions. Nat Rev Microbiol 13: 605-619.

Smith, C.A., Want, E.J., O'Maille, G., Abagyan, R., and Siuzdak, G. (2006) XCMS: processing mass spectrometry data for metabolite profiling using nonlinear peak alignment, matching, and identification. Anal Chem 78: 779-787.

Sud, M., Fahy, E., Cotter, D., Azam, K., Vadivelu, I., Burant, C., et al. (2016) Metabolomics workbench: an international repository for metabolomics data and 
metadata, metabolite standards, protocols, tutorials and training, and analysis tools. Nucleic Acids Res 44: D463D470.

Sumner, L.W., Amberg, A., Barrett, D., Beale, M.H., Beger, R., Daykin, C.A., et al. (2007) Proposed minimum reporting standards for chemical analysis Chemical Analysis Working Group (CAWG) metabolomics standards initiative (MSI). Metabolomics 3: 211-221.

Tandberg, J.I., Lagos, L.X., Langlete, P., Berger, E., Rishovd, A.-L., Roos, N., et al. (2016) Comparative analysis of membrane vesicles from three Piscirickettsia salmonis isolates reveals differences in vesicle characteristics. PLoS ONE 11: e0165099-e0165027.

Tartaglia, N.R., Nicolas, A., Ossemond, J., Nguyen, M.T., FLR, d.C., Gilot, D., et al. (2020) Extracellular vesicles produced by human and animal Staphylococcus aureus strains share a highly conserved core proteome. Sci Rep 10: 1-13.

Tashiro, Y., Hasegawa, Y., Shintani, M., Takaki, K., Ohkuma, M., Kimbara, K., and Futamata, H. (2017) Interaction of bacterial membrane vesicles with specific species and their potential for delivery to target cells. Front Microbiol 8: 813-873.

Ting, C.S., Hsieh, C., Sundararaman, S., Mannella, C., and Marko, M. (2007) Cryo-electron tomography reveals the comparative three-dimensional architecture of Prochlorococcus, a globally important marine Cyanobacterium. J Bacteriol 189: 4485-4493.

Toyofuku, M., Morinaga, K., Hashimoto, Y., Uhl, J., Shimamura, H., Inaba, H., et al. (2017) Membrane vesicle-mediated bacterial communication. ISME J 11: 1504-1509.

Tran, F., and Boedicker, J.Q. (2017) Genetic cargo and bacterial species set the rate of vesicle-mediated horizontal gene transfer. Sci Rep 7: 8813.

Tsugawa, H., Cajka, T., Kind, T., Ma, Y., Higgins, B., Ikeda, K., et al. (2015) MS-DIAL: data-independent MS/MS deconvolution for comprehensive metabolome analysis. Nat Methods 12: $523-526$.

Turner, L., Bitto, N.J., Steer, D.L., Lo, C., D'Costa, K., Ramm, G., et al. (2018) Helicobacter pylori outer membrane vesicle size determines their mechanisms of host cell entry and protein content. Front Immunol 9: 1466.

Van Mooy, B.A.S., Rocap, G., Fredricks, H.F., Evans, C.T., and Devol, A.H. (2006) Sulfolipids dramatically decrease phosphorus demand by picocyanobacteria in oligotrophic marine environments. Proc Natl Acad Sci 103: 86078612.

Volkman, J.K., Barrett, S.M., Blackburn, S.I., Mansour, M.P., Sikes, E.L., and Gelin, F. (1998) Microalgal biomarkers: a review of recent research developments. Org Geochem 29: 1163-1179.

Waterbury, J.B., and Willey, J.M. (1988) Isolation and growth of marine planktonic cyanobacteria. Methods Enzymol 167: 100-105.

White, A.E., Giovannoni, S.J., Zhao, Y., Vergin, K., and Carlson, C.A. (2019) Elemental content and stoichiometry of SAR11 chemoheterotrophic marine bacteria. Limnol Oceanogr 4: 44-51.

Wickham, H. (2009) ggplot2: Elegant Graphics for Data Analysis. New York, NY: Springer.
Yancey, P.H. (2005) Organic osmolytes as compatible, metabolic and counteracting cytoprotectants in high osmolarity and other stresses. J Exp Biol 208: 2819-2830.

Yaron, S., Kolling, G.L., Simon, L., and Matthews, K.R. (2000) Vesicle-mediated transfer of virulence genes from Escherichia coli 0157:H7 to other enteric bacteria. Appl Environ Microbiol 66: 4414-4420.

Yu, N.Y., Wagner, J.R., Laird, M.R., Melli, G., Rey, S., Lo, R., et al. (2010) PSORTb 3.0: improved protein subcellular localization prediction with refined localization subcategories and predictive capabilities for all prokaryotes. Bioinformatics 26: 1608-1615.

Yun, S.H., Lee, S.-Y., Choi, C.W., Lee, H., Ro, H.-J., Jun, S., et al. (2017) Proteomic characterization of the outer membrane vesicle of the halophilic marine bacterium Novosphingobium pentaromativorans US6-1. J Microbiol 55: 56-62.

Zakharzhevskaya, N.B., Vanyushkina, A.A., Altukhov, I.A., Shavarda, A.L., Butenko, I.O., Rakitina, D.V., et al. (2017) Outer membrane vesicles secreted by pathogenic and nonpathogenic Bacteroides fragilis represent different metabolic activities. Sci Rep 7: 16-65.

Zavan, L., Bitto, N.J., Johnston, E.L., Greening, D.W., and Liaskos, M.K. (2019) Helicobacter pylori growth stage determines the size, protein composition, and preferential cargo packaging of outer membrane vesicles. Proteomics 19: e1800209-e1800223.

Zwarycz, A.S., Livingstone, P.G., and Whitworth, D.E. (2020) Within-species variation in OMV cargo proteins: the Myxococcus xanthus OMV pan-proteome. Mol Omics 16: 387-397.

\section{Supporting Information}

Additional Supporting Information may be found in the online version of this article at the publisher's web-site:

Appendix S1: Supporting Information

Supplementary Table S1: Complete dataset of membrane lipids, pigments, and plastoquinone found within Prochlorococcus MIT9312 and MIT9313 cells and vesicles.

Supplementary Table S2: Complete proteomic data for Prochlorococcus MIT9312 and MIT9313 cells and vesicles, including protein and peptide identification and raw spectral counts.

Supplementary Table S3: Relative protein abundances, or biovolume-normalized spectral counts, for Prochlorococcus MIT9312 and MIT9313 cells and vesicles.

Supplementary Table S4: Relative enrichment of proteins in Prochlorococcus vesicles vs. cells.

Supplementary Table S5: Metabolite diversity in Prochlorococcus vesicle and cell samples.

Supplementary Table S6: Full biovolume normalized peak areas for Prochlorococcus vesicles and cells.

Supplementary Table S7: Targeted metabolites detected in vesicles and cells from Prochlorococcus MIT9312 and MIT9313.

Supplementary Table S8: Experimental conditions used to analyse metabolite fractions.

Supplementary Table S9: Parameters for MS-DIAL analysis for each analytical fraction. 